\title{
Ductile Shear Bands in a Naturally Deformed Quartzite
}

\author{
D. GAPAISt and S. H. WHITE‡
}

†Centre Armoricain d'Etude Structurale des Socles, CNRS, Université de Rennes I, Avenue du GI Leclerc 35042 RENNES Cédex, France $\ddagger$ Department of Geology, Royal School of Mines, Imperial College, London SW7 2BP, Great Britain

(Received May 1, 1981; in final form June 29, 1981)

Microscale shear bands are features that often occur oblique to the mylonitic foliation in mylonites. This paper is concerned with such structures within a quartz-mylonite. Geometrical features, microstructures and fabrics associated with shear bands are described. Both optical and transmission electron microscopy have been used. It was observed that the development of shear bands is closely related to (i) the onset of dynamic recrystallisation during deformation, (ii) a change of bulk deformation within the mylonites from relatively homogeneous to inhomogeneous and (iii) a marked softening of the mylonite. Across shear bands, dominant deformation mechanisms change from a dislocation creep type to grain boundary sliding. This induces strong modification of quartz lattice preferred orientations. The asymmetry of quartz fabrics due to shear should generally be favoured by the development of shear band structures. Our results indicate that the production of ductile shear band structures helps to accommodate large strain deformations at low temperatures. Results also indicate that grain and sub-grain sizes are not affected by variations in strain rate.

\section{INTRODUCTION}

Within a given deformed domain, a general shear band structure can be defined as a band-like perturbation characterized by high strains relative to the average strain of the domain, as a result of the concentration of dominant simple shear deformation (Cobbold, 1977a). It is therefore a zone of localized softening and is commonly called a shear zone. Shear bands, which will be considered in this paper, occur as internal structures in foliated rocks. They are small-scale and occur at a low angle (typically less than $45^{\circ}$ ) to the foliation defined by the average grain shape fabric and are generally arranged in a more or less regular array throughout the deformed material. They may display a tendency to form a penetrative deformation structure which has 
led some authors to use the term "shear band foliation" (White, 1979a; White et al., 1980). Comparable structures form during deformation of polycrystalline metals, especially during rolling (Fargette and Whitwham, 1976; Duggan et al., 1978; Dillamore et al., 1979; Malin and Hatherly, 1979) and their similarity to those in rocks has been emphasized (White, 1979a). Shear band development appears as an important process in accommodating large strain deformations at relatively low temperatures and shear bands are common structures in mylonitic zones (Berthe et al., 1979a, b; Watts and Williams, 1979; Platt and Vissers, 1980; Vauchez, 1980; White et al., 1980). In fact, Berthe et al. (1979a, b) have shown that their development can strongly contribute to the process of mylonitisation. Both theoretical and experimental studies (Cobbold, 1977b; Poirier, 1980) show that a general shear band structure corresponds to a strain enhanced rheological instability which reflects the onset of inhomogeneous deformation and allows the material to soften and accommodate further deformation. That is, the development of ductile shear bands should result in the replacement of the earlier microstructure or fabric by another which should be softer. Unfortunately, data on the softening processes that may operate in shear bands are lacking for naturally deformed rocks. Furthermore, the rheological consequences of the development of shear band structures in rocks are still unclear.

This paper provides a detailed description of shear band structures in a quartz-mylonite. The sample was chosen because of (i) the occurrence of well developed shear bands, (ii) a well known geological setting, (iii) the simple mineralogy and (iv) the general interest due to the major role of quartz in the bulk deformation of quartz-rich rocks. The geometry of the macrostructures will be described first and then will follow a detailed description of microstructures and lattice preferred orientations. High voltage electron microscopy was used to compare both microstructures and fabrics inside and outside the bands. Local fabrics will be compared with the bulk fabric of the sample obtained by X-ray texture goniometry. We conclude this contribution with a discussion of (i) the origin of bands, (ii) their rheological significance and (iii) effects on microstructures and fabrics.

\section{STRUCTURAL SETTING OF THE SAMPLE}

The specimen studied belongs to a quartzitic sedimentary series (Armorican quartzite, lower Ordovician age) from the Hercynian belt of Brittany (France). It is composed of quartz ( $85 \%$ ), phyllosilicates (chlorite) and iron oxides (magnetite). In the area, the deformation is associated with a dextral transcurrent shear (Gapais and Le Corre, 1980; Percevault and Cobbold, 1980) which results in a subvertical schistosity and a subhorizontal stretching 
lineation. Within the quartzites, deformation features depend strongly on the intensity of both strain and syntectonic metamorphism (Gapais, 1979a; Gapais and Le Corre, 1980, 1981). Hence, shear bands are only found in quartz-mylonites where detrital porphyroclasts of quartz are preserved; that is, at the vicinity of the biotite isograd. Above the biotite isograd, within more strongly deformed zones, macrostructures are more homogeneous, quartz grains have all been dynamically recrystallised and no shear bands are observed. The temperature dependance of shear band development will be discussed later in the paper.

\section{MACROSTRUCTURES}

The average preferred orientation of grain shapes defines the mylonitic foliation $(\mathrm{Sm})$ and the bulk mineral elongation lineation (Figure 1). Shear bands (Ss) and mylonitic foliation intersect around the intermediate strain axis (Y). The relationship between shear bands and mylonitic foliation is the one which is classically observed in a shear deformation, the direction and the sense of shear being as indicated in Figure 1 (Berthe et al., 1979b; White, 1979a; White et al., 1980). The spacing between bands is more or less regular (Figure 1). Although it varies between $90 \mu \mathrm{m}$ and $650 \mu \mathrm{m}$, most are around $280 \mu \mathrm{m}$. The width of the bands is typically $60 \mu \mathrm{m}$. Most of the bands are at $35^{\circ}$ to the mylonitic foliation, which can vary between $15^{\circ}$ and $55^{\circ}$. Where affected by a shear band, the mylonitic foliation trends into parallelism with the shear band boundary (Figures 1 and 2). The pattern is quite com-

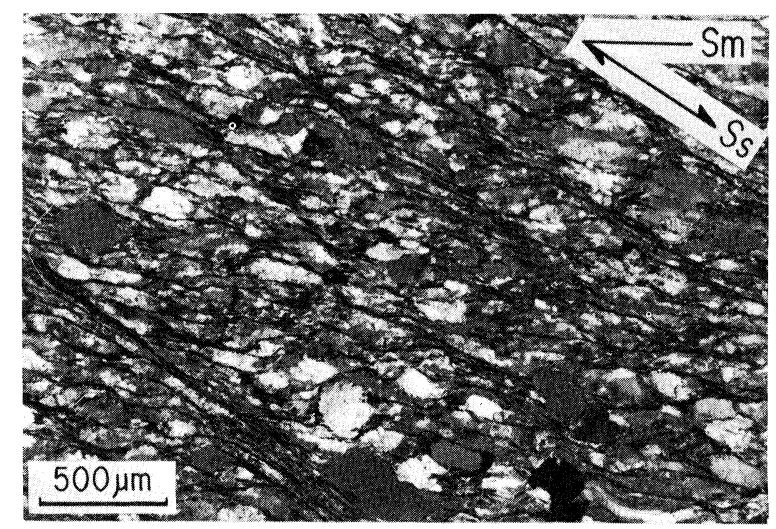

FIGURE 1 Optical micrograph of shear band structures within the quartz-mylonite studied (polarized light; section perpendicular to the intermediate strain axis). The angle between shear bands (Ss) and mylonitic foliation ( $\mathrm{Sm}$ ) and the spacing between bands are more or less regular. The acute angle between Ss and Sm faces in the sense of shear. 
parable to that observed in continuous ductile shear zones as described by Ramsay and Graham (1970). Assuming the deformation is a simple shear parallel to the boundaries of the band, the maximum amount of differential shear strain $(\gamma)$ can be estimated from the angle between shear band boundaries and the mylonitic foliation outside and in the centre of the band (Ramsay, 1967, Eq. 3-71). Measurements on a large number of bands led to estimates ranging from $\gamma=3.5-4$.

\section{MICROSTRUCTURES}

Optical microstructures outside and in the centre of the band are markedly different (Figures 1 and 2). Outside the bands, old porphyroclasts of quartz are preserved. Internal deformation features (undulatory extinction and deformation bands) reveal a well developed sub-grain structure. Dynamic recrystallisation has occurred at grain boundaries. Phyllosilicates are uncommon and often typically detrital. No marked variations in the microstructure are noticeable optically adjacent to shear band boundaries. On the other hand, the inside of the shear bands is characterized by very fine-grained quartz and a relative increase in the amount of phyllosilicates which occur as small neoblasts (Figures 1 and 2).

Under the high voltage electron microscope (operating at $1000 \mathrm{KV}$ ), quartz grains outside of the shear bands have typical core and mantle structures (Figure 3) (White, 1976). They have high densities of tangled dislocations (Figure 4a). Sub-grains are present in all grains and in a given grain have different morphologies in core and mantle areas. In cores, most sub-grains are elongated parallel to prism planes, whereas in mantles they are equi-

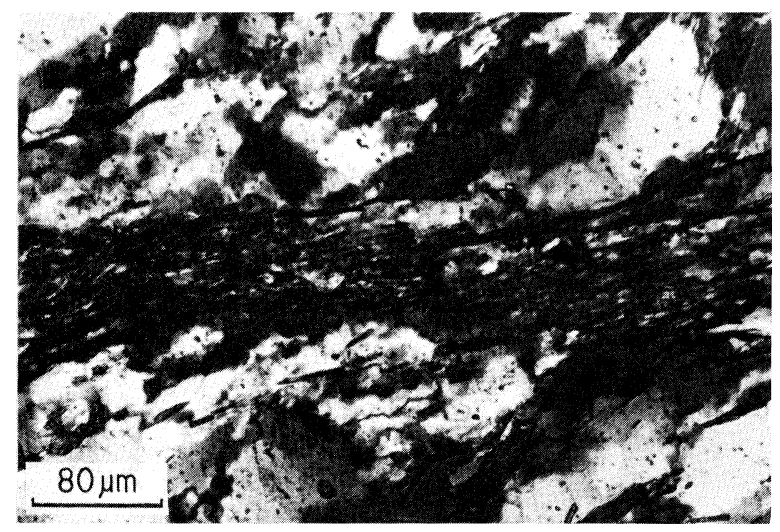

FIGURE 2 Optical micrograph showing the detail within a typical shear band from the quartzmylonite (polarized light; section perpendicular to the intermediate strain axis). The mylonitic foliation $\mathrm{Sm}$, which is outlined by phyllosilicates, adopts a sigmoidal trend across the band. 


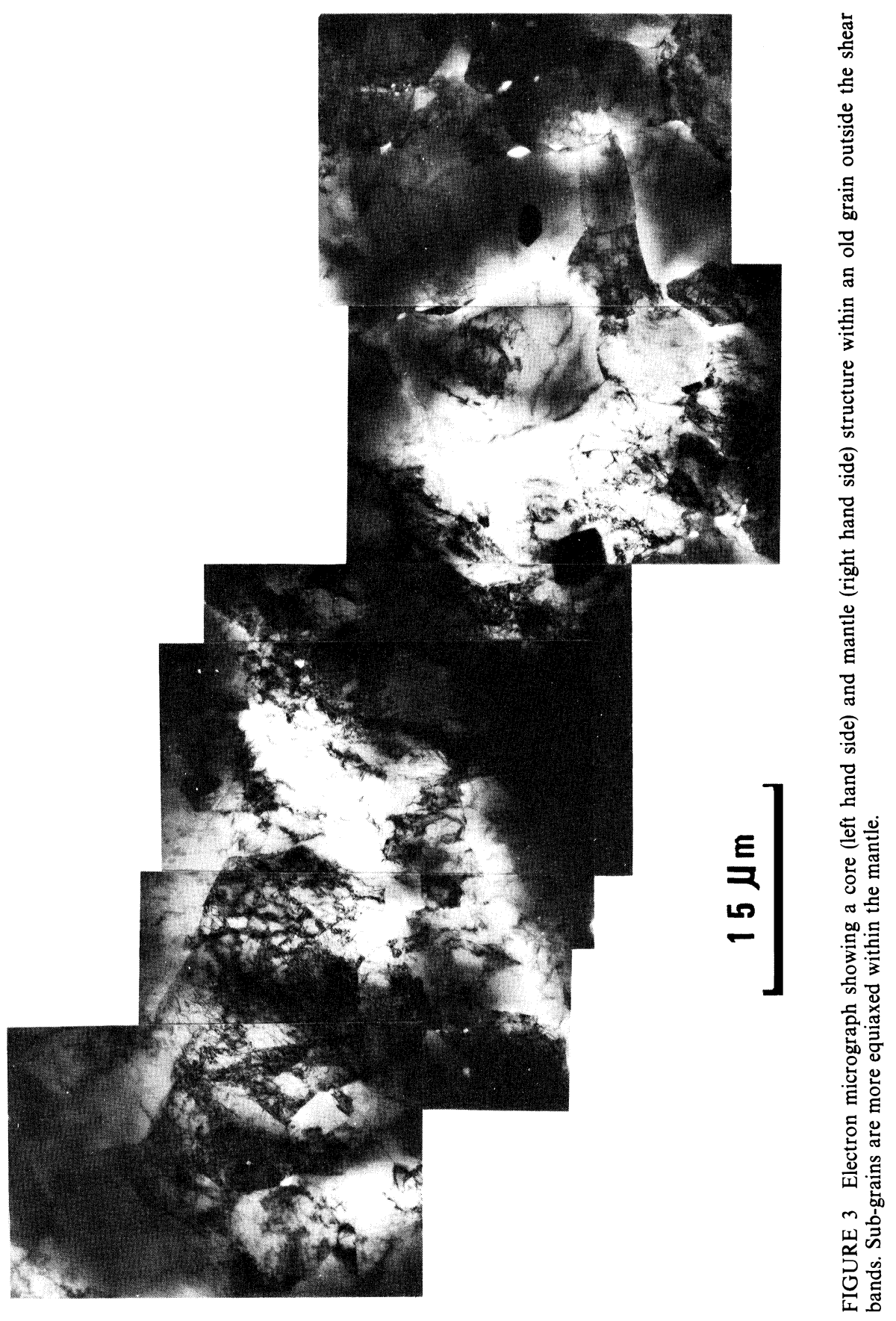



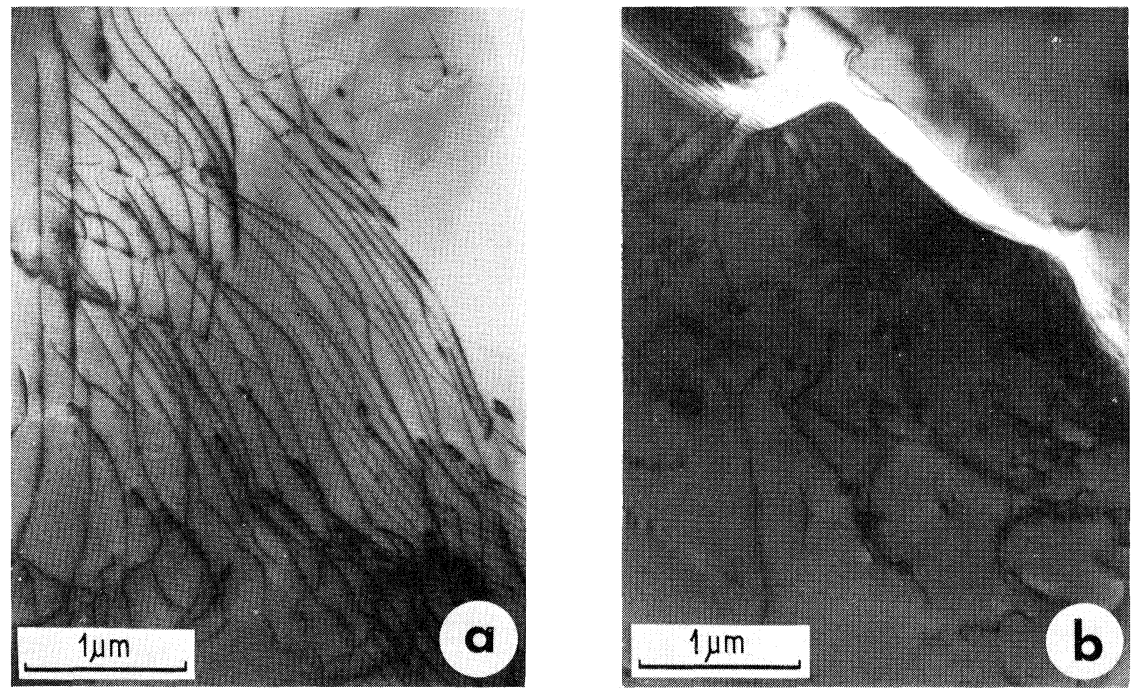

FIGURE 4 Electron micrographs showing typical dislocation features. Figure a: within an old grain outside the shear bands. Figure b: within a new recrystallised grain in a shear band.

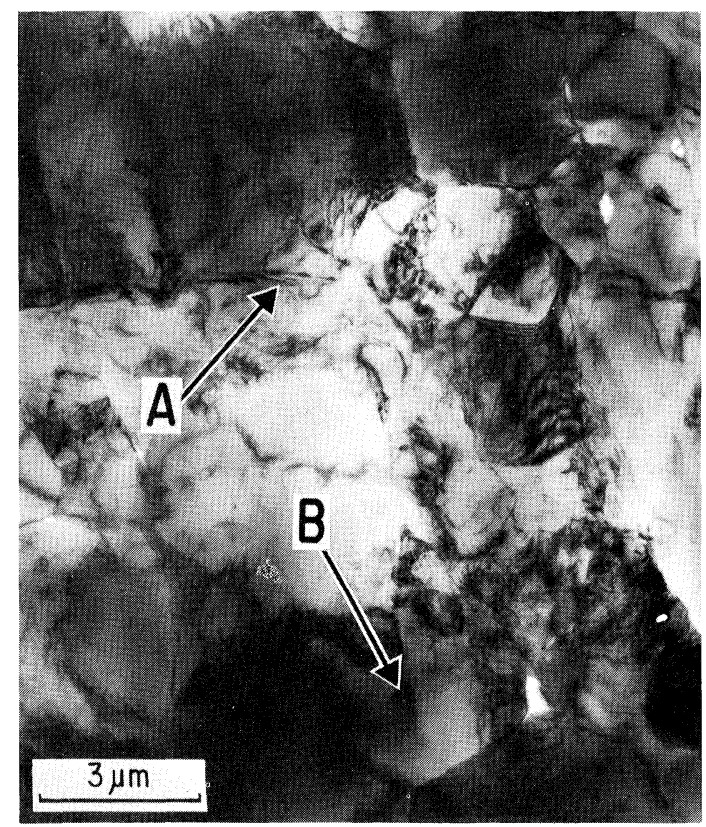

FIGURE 5 Electron micrograph showing a typical sub-structure within the mantle area of an old grain outside the shear bands. The main set of sub-grain boundaries, and of boundaries of new grains derived from sub-grains, (B) corresponds to prism planes or combinations of prisms and rhombs. The other set (A) corresponds mainly to rhomb planes. 
dimensional or rectangular in shape, primarily due to the occurrence of two principal sets of sub-grain boundaries (Figures 3 and 5). One set (A on Figure 5) corresponds mainly to rhomb planes with their normals at high angle to both foliation and lineation. The other set (B on Figure 5) is at a high angle to the mylonitic foliation and corresponds to prism planes or combinations of prisms and rhombs. This latter set is generally better developed and leads to sub-grains generally slightly elongated parallel to the $\mathrm{c}$ axis. The misorientation of subgrains increases towards the grain boundaries where new grains develop. Both the new grains and sub-grains are very small and have a similar size (Table 1).

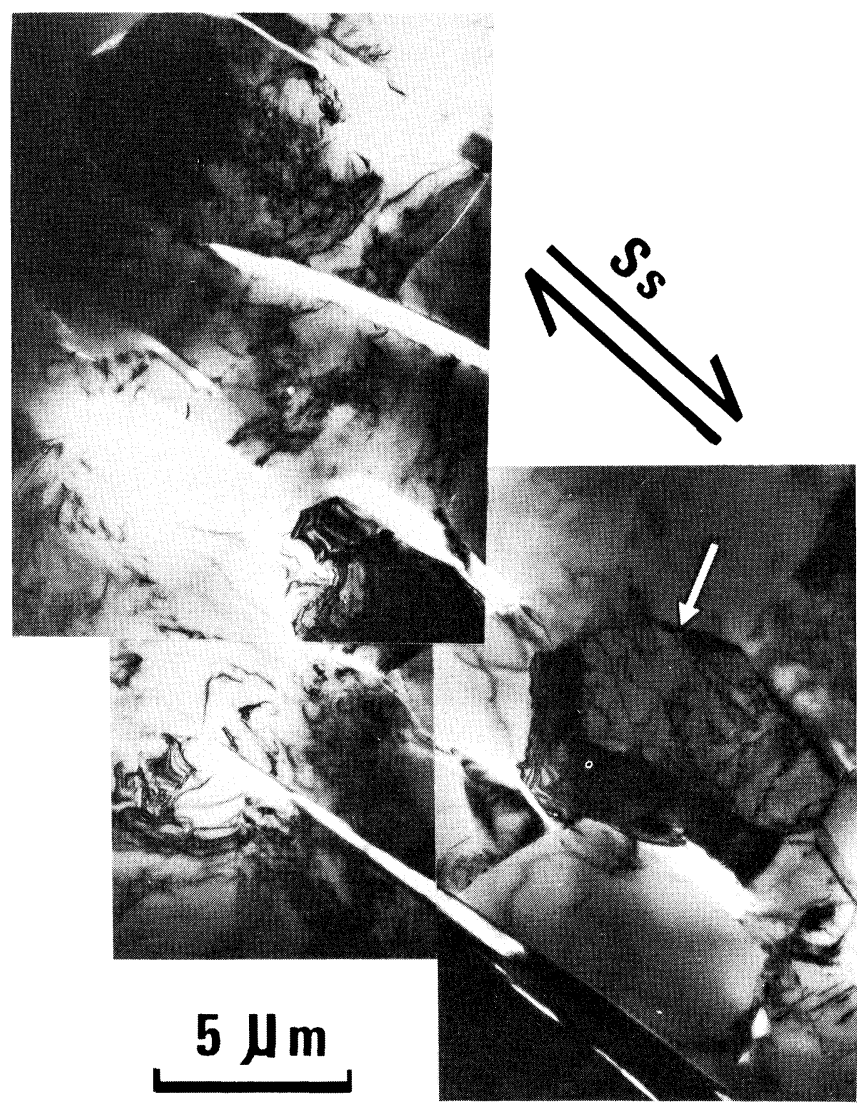

FIGURE 6 Electron micrograph showing typical recrystallised microstructures within the shear bands. The shear direction is outlined by small phyllosilicates now marked by voids because of phyllosilicate loss during ion thinning. Most grains have rectangular shapes. Note the tendency for grain boundaries to be aligned parallel to the shear direction. Some grains show many dislocations often concentrated at grain margins (grain arrowed). 
Quartz grains within the bands are small: their mean size is the same as sub-grains and new grains sizes outside the bands (Table 1). They tend to be equidimensional to slightly elongated parallel to the shear direction, which is marked by phyllosilicates (Figure 6), and have smooth grain boundaries which tend to line up with the shear direction. Unbound dislocations, but not sub-grains, occur in the small grains. The dislocation density varies from grain to grain. Those with smooth grain boundaries have densities lower than grains outside the bands whereas grains with irregular boundaries have higher densities. In such grains the dislocations are generally concentrated at grain boundaries (Figures $4 \mathrm{~b}$ and 6 ). All boundaries contained voids (bubbles) in greater numbers than outside the bands.

\section{FABRICS}

\section{Bulk fabric}

Bulk quartz fabrics were studied by X-ray texture goniometry, using the reflexion mode (Schultz, 1949; Baker and Wenk, 1972; Gapais, 1979b). Preferred orientations of $\langle\cdot 10 \overline{1} 4\rangle$ axes and $\langle a\rangle$ axes, which have been fully described elsewhere (Gapais, 1979a), are presented here (Figure 7). The former, which refers to crystallographic axes at $17.20^{\circ}$ to the $\mathrm{c}$ axis, provide a qualitative description of the preferred orientations of $\mathrm{c}$ axes (Rieckels and Baker, 1977; Gapais, 1979a). These are lying at a high angle to the mineral elongation lineation and tend to concentrate around the normal to the mylonitic foliation (Figure $7 \mathrm{a}$ ). The $\langle\mathrm{a}\rangle$ axes pattern (Figure $7 \mathrm{~b}$ ) shows a maximum oblique to the lineation, as usual in the quartz mylonites considered here (Gapais, 1979a). The pattern is asymmetric, indicating a comporient of dextral shear (Bouchez, 1978; Gapais, 1979b; Lister and Williams, 1979). A consistent sense of shear has been found on a regional scale (Gapais, 1979b; Gapais and Le Corre, 1980).

TABLE I

Mean size of microstructural features $(\mu \mathrm{m})$ outside and inside the shear bands. Measurements by transmission electron microscopy.

\begin{tabular}{|c|c|c|}
\hline \multicolumn{3}{|c|}{ Grain and Sub-grain sizes $(\mu \mathrm{m})$} \\
\hline \multicolumn{2}{|c|}{ Outside shear bands } & Inside shear bands \\
\hline $\begin{array}{l}\text { Sub-grain } \\
\text { size } \\
\text { (180 meas.) }\end{array}$ & $\begin{array}{l}\text { new grain } \\
\text { size } \\
\text { ( } 35 \text { meas.) }\end{array}$ & $\begin{array}{c}\text { grain } \\
\text { size } \\
(90 \text { meas.) }\end{array}$ \\
\hline 4.8 & 5.0 & 4.7 \\
\hline
\end{tabular}




\section{Fabric within the shear bands}

Pole figures described above cannot distinguish between fabrics inside and outside the shear bands. Also the fine grain size of material within the shear bands precludes optical fabric analysis. However, the use of a sensitive tint in the optical microscope shows that fabrics are different inside and outside the bands. This was verified by high voltage electron microscopy. The HVEM was used in a way comparable to an optical universal stage. The orientation of each particular grain was obtained by taking a selected area of diffraction pattern (prominent pole parallel to the beam direction) which was referred to a reference plane containing both the mineral elongation lineation and the shear direction in the bands. Diffraction patterns were indexed and the orientations of both shear direction in the bands and normal to shear plane with respect to the crystallographic frame were deduced. Inverse pole figures were constructed for these two directions. This was done for new grains inside and outside the shear bands (Figure 8). Insufficient grains were analysed for quantitative analysis because of the tendency to etch out the shear bands during foil preparation by ion thinning. However, they can be used qualitatively as they relate to measurements in several areas in the sample and are consistent with the information obtained optically (Figure 9).

Outside the bands, the $\mathrm{c}$ axis of new grains tends to be at a relatively high angle (about $65^{\circ}$ ) to the shear direction in the band (Figures 8a, b and 9a). The orientations are consistent with the preferred orientations observed for the bulk sample (Figure 7). This probably reflects host control by the old grains.

Inside the bands, quartz lattice orientations are different. The $\mathrm{c}$ axis tends to be at a low angle (less than $45^{\circ}$ ) to the shear direction. Furthermore, the pole-free areas in the inverse pole figures tend to be complementary to those for the new grains outside the bands (Figure 8). This is also suggested by optical results (Figure 9).

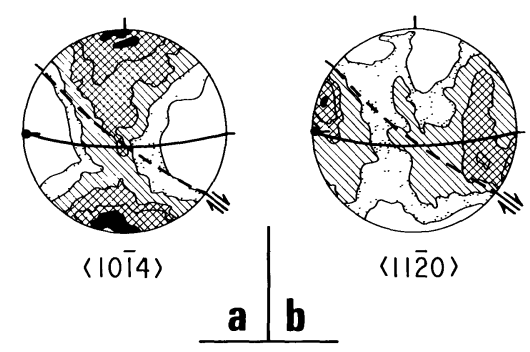

FIGURE 7 Bulk lattice preferred orientations of quartz measured by texture goniometry. Figure a: $\langle 10 \overline{1} 4\rangle$ axes; maximum density, $1.9 \times$ uniform distribution (u.d.). Figure b: $\langle a\rangle$ axes; maximum density, $1.65 \times$ u.d. The mylonitic foliation (black line) and the orientation of shear bands (dotted line) are indicated. The mineral elongation lineation is E.W. (After Gapais, 1979a). 


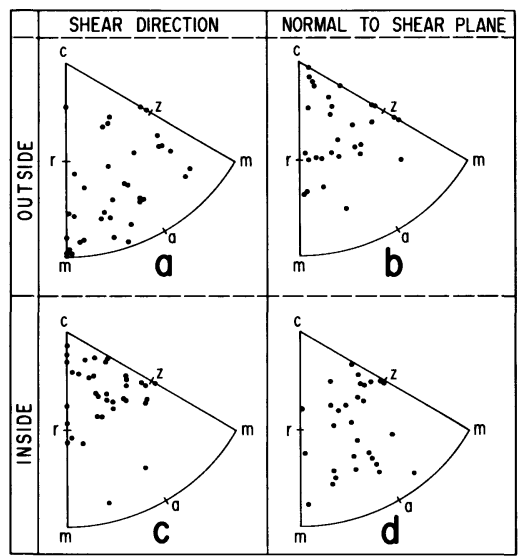

FIGURE 8 Inverse pole figures for the orientation of new recrystallised grains (measurements by transmission electron microscopy) outside (Figures a and b) and inside (Figures $c$ and d) shear bands. Figures a and c: orientation of the shear direction; Figures $b$ and d: orientation of the normals to shear planes. Stereographic projections, lower hemisphere.

The reorientation of the $c$ axes in the vicinity of a shear band can be locally observed and related to the amount of shear (Figure 10). It can be seen that a significant rotation occurs in the grain mantles. Further rotation, which brings the $\mathrm{c}$ axes towards the shear direction, occurs in the recrystallised domain affected by the shear band. The sense of rotation is constant and is the same as the sense of shear. The rotations can be very large (up to $150^{\circ}$ ), depending upon the initial orientation of the $\mathrm{c}$ axis in the old grain. However, no quantitative relationship has been found between the extent of fabric rotation and the amount of shear.

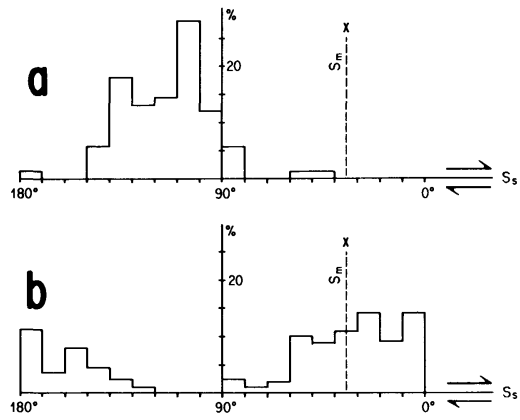

FIGURE 9 Histograms for the orientation of the projection of the $\mathrm{c}$ axes within the plane perpendicular to shear bands (optical measurements using a sensitive tint). The trace of the mylonitic foliation $(\mathrm{Sm})$ and of the shear bands $(\mathrm{Ss})$ are marked. The mineral elongation lineation $(x)$ is indicated. Figure a: orientations outside the shear bands (measurements of old grains). Figure b: orientations inside the shear bands (measurements for clusters of new grains). 

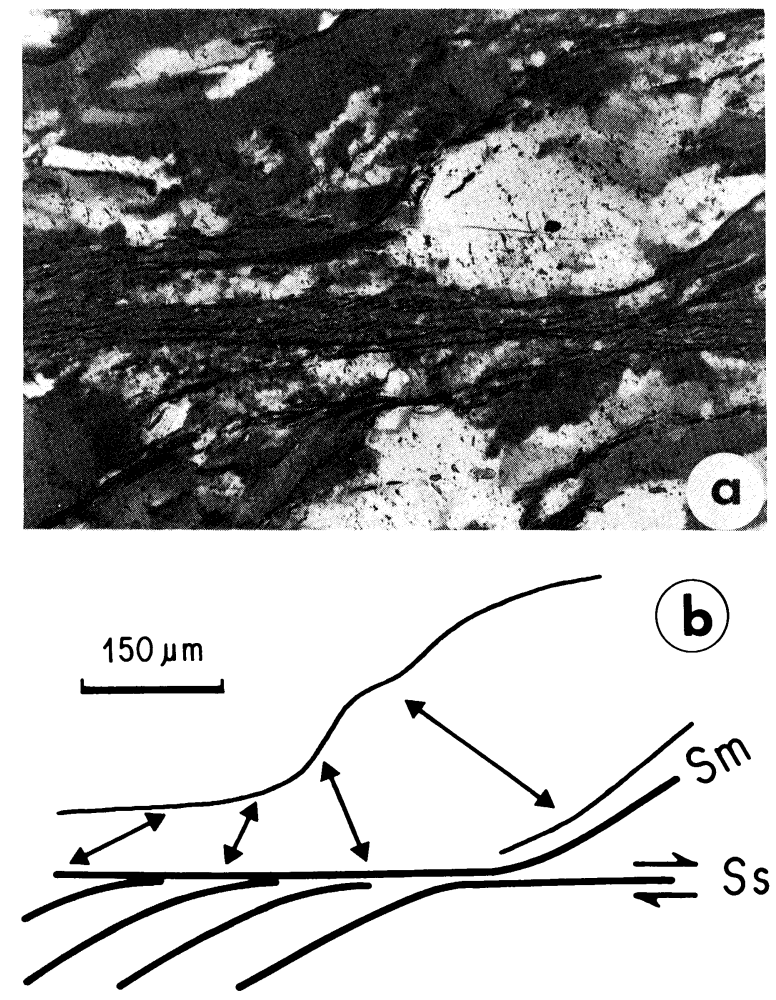

FIGURE 10 Deformation of quartz grains and associated change in $\mathrm{c}$ axis orientation at the vicinity of a dextral shear band. Figure a: optical micrograph showing the stretching and recrystallization of a quartz grain as it passes into a shear band (polarized light; section perpendicular to the intermediate strain axis). Figure b: sketch of the micrograph in Figure a. The approximate outline of an old grain and its recrystallized tail is sketched. The recrystallised domain is elongated in the shear direction. Ss: shear band axis. Sm: trace of the mylonitic foliation; directions arrowed: trace of the projection of the $\mathrm{c}$ axes (local mean $\mathrm{c}$ axis orientations in the old grain; average for clusters of new grains in the recrystallised part; measurements using sensitive tint).

\section{DISCUSSION}

\section{Origin of the shear bands}

Microstructures outside the shear bands indicate a dislocation creep type of deformation with associated dynamic recrystallisation (Bell and Etheridge, 1973; White, 1977). Results indicate that the development of the bands is strongly related to the onset of late stage dynamic recrystallisation and neomineralisation in the mylonite, both preferentially localized at the edges of original grains (see also White, 1976). They result from the development of 
core and mantle structures (White, 1976). Within the core, a unique slip system tends to be dominant, whereas harder slip systems may operate in the mantle where deformation concentrates (see also White et al., 1979). This is indicated by different sub-grain shapes in the core and in the mantle, as described above. Deformation is accommodated in the mantles in such a way that strain compatibility in the grains and between adjacent grains is respected. As only a few slip systems (less than five) can be activated, this is obtained through rotations of the lattice at grain margins and results in significant misorientations which favour the development of new grains at grain boundaries (White, 1973, 1977; Poirier and Guillope, 1979). In the present case, progressive misorientation of sub-grains appears as a dominant process of dynamic recrystallisation. The shear bands develop as a result of the linking of zones of recrystallized grain mantles. The rotations in the mantles and subsequently those in the new grains derived from the mantles provide a structural softening (see also Burrows, 1979). In other words, due to fabric anisotropy and limited operating slip systems, the deformation becomes heterogeneous and concentrates at grain margins which recrystallize, the softening associated with shear band development relying on the production of a critical proportion of recrystallized grains.

Our results indicate that the shear bands in the rocks studied developed during the same deformation that produced the mylonitic foliation but at a late stage, similar to that reported by other workers (Berthe et al., 1979a, b; White, 1979a; Platt and Vissers, 1980; White et al., 1980). These observations concur with field data (Gapais, 1979b; Gapais and Le Corre, 1980). The shear band development appears to be associated with a low temperature during deformation but not a temperature drop as reported for shear band formation in the Cap de Creus mylonites (see White, 1979a). In the region considered here no shear bands are present in rocks from above the biotite isograde. In fact, in these rocks, the deformation is more homogeneous due to more intense recrystallization, whereas in rocks below the biotite isograd recrystallization is mainly limited to shear bands. Also the fabric changes at the biotite isograd. Therefore it is not possible to uniquely determine if the shear band formation is tied in with limited recrystallization due to low deformation temperatures or to the onset of a change in slip systems as evidenced by the fabric transition at the biotite isograd (Gapais, 1979a).

\section{Softening processes in the shear bands}

As argued above, dynamic recrystallization is found to provide the necessary instability to produce shear bands. However, the operating deformation mechanisms within the recrystallised zones must allow a marked softening which leads to the localisation of strain in the bands. As will be discussed 
in a following section, geometric softening may have occurred during the earlier stages of shear band development but microstructural evidence indicates that dominant grain boundary sliding has been the main softening mechanism in the shear bands. The following criteria, discussed by White (1979b) support this conclusion. They are - (i) grain size less or, at most, the same as the stable sub-grain size for a given temperature and stress, (ii) rectangular or square grains with smooth grain boundaries aligned parallel to the shear direction, (iii) grain shapes unrelated to the state of finite strain. Also, the dependence of dislocation density on grain shape together with a tendency for dislocations to be concentrated at grain margins, are consistent with a mechanism of dislocation accommodated grain boundary sliding (Schmid et al., 1977; White, 1979b), but not proof of such a mechanism (White, 1977). A change in deformation mechanism from a dislocation creep type to dominant grain boundary sliding is a plausible explanation for the concentration of deformation in the shear bands. The small average width of bands suggests that no marked widening has occurred during deformation. This is consistent with grain boundary sliding as no hardening is to be expected. Also grain boundary sliding, which is a most efficient softening mechanism (White, 1976, 1977, 1979b; Schmid et al., 1977; Etheridge and Wilkie, 1979), is likely to be favoured by low temperature during deformation (White et al., 1980). The large amount of phyllosilicates and voids along grain boundaries have probably contributed to maintain a small grain size in the shear bands.

\section{Grain size in shear bands}

The size of the recrystallized grains in mylonites is thought to be dominantly stress-controlled with a smaller temperature effect. An influence by strain rate has been tentatively suggested, but it is difficult to separate stress and temperature influences in experiments, as increased strain rate is achieved by either increasing temperature at constant stress or stress at constant temperature. The shear bands provide an opportunity to determine any influence of strain rate on grain size. As stated earlier, shear bands develop because bulk deformation cannot accommodate the imposed strain rate, i.e. it is accommodated by deformation in the shear bands. Given that the average width of bands in the mylonite studied is $60 \mu \mathrm{m}$ and they are $280 \mu \mathrm{m}$ apart, then the strain rate needs to be five times faster in the bands than that for bulk deformation. If grain size is strain rate dependent, the grain size in the shear bands should be smaller than the recrystallized grain size in the bulk material. However, these have similar values which are also equal to the sub-grain size in the grain mantles. It is concluded from this that an equilibrium size has developed which reflects the stress as this should be more or less constant throughout the bulk of the material (Cobbold, 1977b). 


\section{Effects of shear bands on the fabrics}

The bulk fabric is thought to be due to dominant basal 〈a〉 slip (Gapais, 1979a). The presence of rhomb sub-grain walls in the quartz grain mantles indicates slip activity on the rhomb probably in an $\langle a\rangle$ direction (see also White et al., 1979). Our data shows that there is a marked fabric difference between the quartz grains inside and outside the shear bands. There is a clustering of the $\mathrm{c}$ and rhomb directions around the shear direction. The re-orientations could be explained by intra-crystalline slip and/or by grain rotations of the rigid-body type accommodated by grain boundary sliding.

Geometrical considerations resulting from compatibility requirements between adjacent grains will govern both types of rotation. Figure 10 indicates that the re-orientation of the quartz grains takes place in two stages, firstly in the old grain mantles and secondly in the recrystallized grains themselves. The first stage must be accomplished by intracrystalline slip. The rotation at this stage will generally be dextral and will tend to bring the basal planes at a low angle to the dextral shear plane. As a result, the grain mantles become well orientated for basal slip. Because of host grain control, new grains recrystallizing from the mantles should have rather similar orientations. However, our data indicates that the recrystallized grains are orientated for prism $\langle c\rangle$ or rhomb $\langle\mathrm{c}+\mathrm{a}\rangle$ slip. Both systems indicate a temperature increase for which there is no evidence.

The recrystallized grains develop from the rotation of sub-grains which tend to be bounded by prism and rhomb planes and which, consequently, tend to be elongated parallel to the $\mathrm{c}$ axis. The new grains mimic the morphology of the sub-grains and if rotated (rigid body rotation) during shearing they will tend to align with the c-axis parallel to the shear direction. This fabric would also ensure that the maximum area of grain boundaries is aligned for easy sliding. This latter explanation is in better agreement with our observations than is the former.

The existence of a separate fabric in the shear bands related to movement within the bands rather than flow in the bulk of the mylonite will introduce complexities into fabric diagrams. The extent will largely depend upon the volume of material in the shear bands. This can be seen in the study of Berthe et al. (1979b) who found that fabric obliquity increased with an increase in the number of shear bands present. A clear demonstration of shear bands causing fabric obliquity has been given by Sander (1970, Pl. Ib). The rotation of grains by shear bands also suggests that the sense of obliquity will be the same as that of the shearing in the mylonite zone. This is commonly observed in mylonite fabrics (Simpson, 1980) and a weak obliquity can be seen in the fabrics in Figure $7 \mathrm{~b}$, the weakness probably being due to the small volume of material in the bands studied. 


\section{CONCLUSIONS}

1) Shear bands are the result of inhomogeneous deformation. They develop after a critical amount of strain above which the rock is incapable of accommodating, homogeneously, the bulk deformation. In the example studied, few operating slip systems and a low recrystallisation rate have probably enhanced the development of the bands.

2) The onset of dynamic recrystallisation at the margins of old grains provided zones of fine-grained quartz from which shear bands are initiated.

3) The development of shear bands is inferred to be associated with a marked softening of the mylonite. In the example studied, deformation mechanisms change within the bands. Grain boundary sliding is the dominant deformation mechanism within the bands. The resulting strain rate gradient across the bands accounts for the observed amounts of differential shear. No stress gradient across bands is needed to account for their development (Cobbold, 1977b).

4) The softening mechanisms that may operate in shear bands are closely related to the general conditions of flow during mylonitisation. A knowledge of these is therefore important to characterize the history of a mylonite zone.

5) A change in quartz lattice preferred orientations occurs across the bands. It results in large lattice rotations, which are controlled by the sense of shear within the bands. This is thought to be mainly due to grain rotations accompanying grain boundary sliding.

6) The development of shear band structures during progressive shearing should produce an asymmetry of quartz c-axis fabrics with respect to the mylonitic foliation. The asymmetry should have the same sense as that of the shearing.

7) Grain and sub-grain sizes in the quartzite studied reflect the stress and do not appear to be dependent on the strain rate.

8) Transmission electron microscopy provides a good tool for detailed fabric studies in fine-grained materials and which cannot be achieved by means of standard techniques of fabric analysis.

\section{Acknowledgements}

The authors are grateful to their colleagues at Rennes and London for helpful discussions. P. Cobbold and C. Willaime critically read the manuscript. D.G. was supported by a Royal Society research fellowship. He is indebted to his colleagues at Imperial College, London, where this work was undertaken. The research was supported by NERC grant GR3 3848. 


\section{References}

Baker, D. W. and Wenk, H. R. Preferred orientation in a low-symmetry quartz mylonite. J. Geol. 80, 81-105 (1972).

Bell, T. H. and Etheridge, M. A. Microstructure of mylonites and their descriptive terminology. Lithos 6, 337-348 (1973).

Berthe, D., Choukroune, P. and Jegouzo, P. Orthogneiss, mylonite and non coaxial deformation of granites: the example of the South Armorican Shear Zone. J. Struct. Geol. 1, 31-42 (1979a).

Berthe, D., Choukroune, P. and Gapais, D. Orientations préférentielles du quartz et orthogneissification progressive en régime cisaillant: l'exemple du cisaillement sudarmoricain. Bull. Minéral. 102, 265-272 (1979b).

Bouchez, J. L. Preferred orientations of quartz $\langle a\rangle$ axes in some tectonites: kinematic inferences. Tectonophysics 49, T25-T30 (1978).

Burrows, S. E. Dynamic recrystallization of a magnesium alloy. Unpublished Ph.D. thesis, University of London (1979).

Cobbold, P. R. Description and origin of banded deformation structures. I. Regional strain, local perturbations, and deformation bands. Can. J. Earth Sci. 14, 1721-1731 (1977a).

Cobbold, P. R. Description and origin of banded deformation structures. II. Rheology and the growth of banded perturbations. Can. J. Earth Sci. 14, 2510-2523 (1977b).

Dillamore, I. L., Roberts, J. G. and Bush, A. C. Occurrence of shear bands in heavily rolled cubic metals. Metal Sci. J. 13, 73-77 (1979).

Duggan, B. J., Hatherly, M., Hutchinson, W. B. and Wakefield, P. T. Deformation structures and textures in cold-rolled 70:30 brass. Metal Sci. J. 12, 343-351 (1978).

Etheridge, M. A. and Wilkie, J. C. Grainsize reduction, grain boundary sliding and the flow strength of mylonites. Tectonophysics 58, 159-178 (1979).

Fargette, B. and Whitwham, D. Déformation plastique du laiton CuZn30 au cours de déformations élevées par laminage. Rev. Metall. Mem. Sci. 73, 197-206 (1976).

Gapais, D. Déformation progressive d'un quartzite dans une zone plissée (segment hercynien de Bretagne Centrale). Bull. Minéral. 102, 249-264 (1979a).

Gapais, D. Orientations préférentielles de réseau et déformations naturelles. Applications aux quartzites (segment hercynien de Bretagne Centrale) et aux amphibolites (couverture des dômes gneissiques de Kuopio-Finlande). Thesis, troisième cycle. Université de Rennes. (1979b).

Gapais, D. and Le Corre, C. Is the Hercynian belt of Brittany a major shear zone? Nature, Lond. 288, 574-576 (1980).

Gapais, D. and Le Corre, C. Processus de déformation à basse température dans des argilosiltites et des quartzites: effets de la lithologie et des conditions thermiques. Rev. Géol. Dyn. Géogr. Phys. in press (1981).

Lister, G. S. and Williams, P. F. Fabric development in shear zones: theoretical controls and observed phenomena. J. Struct. Geol. 1, 283-297 (1979).

Malin, A. S. and Hatherly, M. Microstructure of cold-rolled copper. Metal. Sci. J. 13, 463-472 (1979).

Percevault, M. N. and Cobbold, P. R. Les résultats de la déformation inverse démontrent-ils l'existence d'une déformation cisaillante transcurrente sud-armoricaine? 8ème Réun. Ann. Sci. Terre, Marseille, Soc. Geol. Fr. (éd.), 275 (1980).

Platt, J. P. and Vissers, R. L. M. Extensional structures in anisotropic rocks. J. Struct. Geol. 2, 397-410 (1980).

Poirier, J. P. Shear localization and shear instability in materials in the ductile field. J. Struct. Geol. 2, 135-142 (1980).

Poirier, J. P. and Guillope, M. Deformation induced recrystallization of minerals. Bull. Mineral. 102, 67-74 (1979).

Ramsay, J. G. Folding and fracturing of rocks. McGraw-Hill, New York, 568 pp (1967).

Ramsay, J. G. and Graham, R. H. Strain variations in shear belts. Can. J. Earth Sci. 7, 786-813 (1970).

Rieckels, L. M. and Baker, D. W. The origin of the double maximum pattern of optic axes in quartzite mylonite. J. Geol. 85, 1-14 (1977). 
Sander, B. An introduction to the study of fabrics of geological bodies. Pergamon Press, London, $641 \mathrm{pp}(1970)$.

Schmid, S. M., Boland, J. N. and Paterson, M. S. Superplastic flow in fine grained limestone. Tectonophysics 43, 257-292 (1977).

Schultz, L. G. A direct method of determining preferred orientation of a flat reflexion sample using a geiger counter X-ray spectrometer. J. Appl. Phys. 20, 1030-1033 (1949).

Simpson, C. Oblique girdle orientation patterns of quartz C-axes from a shear zone in the basement core of the Maggia Nappe Ticino, Switzerland. J. Struct. Geol. 2, 243-247 (1980).

Vauchez, A. Ribbon texture and deformation mechanisms of quartz in a mylonitized granite of great Kabylie (Algeria). Tectonophysics 67, 1-12 (1980).

Watts, M. J. and Williams, G. D. Fault rocks as indicators of progressive shear deformation in the Guingamp region, Brittany. J. Struct. Geol. 1, 323-332 (1979).

White, S. H. Syntectonic recrystallization and texture development in quartz. Nature, Lond. 244, 276-278 (1973).

White, S. H. The effects of strain on the microstructures, fabrics, and deformation mechanisms in quartzites. Phil. Trans. R. Soc. Lond. A 283, 69-86 (1976).

White, S. H. Geological significance of recovery and recrystallization processes in quartz. Tectonophysics 39, 143-170 (1977).

White, S. H. Large strain deformation. J. Struct. Geol. 1, 333-339 (1979a).

White, S. H. Grain and sub-grain size variations across a mylonite zone. Contr. Mineral. Petrol. 70, 193-202 (1979b).

White, S. H., Burrows, S. E. and Carreras, J. Textural and microstructural development in a naturally deformed quartzite: a metallurgical approach. In: Textures in materials, SpringerVerlag, Berlin, 211-220 (1979).

White, S. H., Burrows, S. E., Carreras, J., Shaw, N. D. and Humphreys, F. J. On mylonites in ductile shear zones. J. Struct. Geol. 2, 175-187 (1980). 